\title{
Impact of the Content of LaNd on Physical Properties of Zn9.3Al7Cu Solder
}

\author{
Shitao $\mathrm{Ma}^{1,2, a}$, Yanfu Yan ${ }^{1, \mathrm{~b}, ~ *}$ and Jinhong Zhu ${ }^{1, \mathrm{c}}$ \\ ${ }^{1}$ Henan University of Science and Technology, Luoyang 471003, China \\ ${ }^{2}$ Collaborative Innovation Center of Nonferrous Metal Generic Technology, Henan Province \\ amst07140505@126.com, ${ }^{\mathrm{b}}$ yanyanfu1970@sina.com, ${ }^{\mathrm{c} z j h 163 c n @ 163 . c o m}$
}

Keywords: Zn9.3Al7Cu solder, RE LaNd, density, conductivity.

\begin{abstract}
In the paper a new solder is made by adding trace LaNd into $\mathrm{Zn} 9.3 \mathrm{Al} 7 \mathrm{Cu}$ alloy to improve the performance through alloying principle. The impact of the content of LaNd on physical properties of Zn9.3Al7Cu solder is investigated. Results show that the density of solder alloys increases with the increasing of the content of rare earth LaNd, When RE content is 0.5wt.\%,the Zn9.3Al7Cu0.5RE has the greatest density, is $6.29 \mathrm{~g} / \mathrm{cm} 3$ which is about $1.73 \%$ bigger than the matrix solder; Adding rare earth LaNd has a great influence on the resistivity of solder alloy, the resistivity of solder alloys increases with the increasing of the content of rare earth LaNd, the resistivity reaches the greatest value When RE LaNd content is $0.5 \mathrm{wt}$.\%,he greatest value is $0.2 \times 10-6 \Omega \mathrm{m}$ which is about $11 \%$ bigger than the matrix solder.
\end{abstract}

\section{Introduction}

Copper and aluminum develops rapidly because of their good electrical conductivity, thermal conductivity, corrosion resistance and other excellent properties, widely used in the national economy of various fields and national defense construction, their consumption are second only to iron and steel materials, becomes the second big metal materials[1-2]because market price, density of aluminum is about $1 / 3$ for copper, aluminum product cost is $1 / 9$ of the same copper products, therefore people use " aluminum instead of copper" technology to reduce the production cost in many industries. In addition, the connection of copper/aluminum dissimilar materials also can save resources, make full use of the performance advantages of copper and aluminum [3].Statistics shows, the application of copper aluminum dissimilar metal joints will account for $5.8 \%$ in commonly use dissimilar metal joints in the 21st century [4].Brazing method is a promising copper aluminum connection technology because of low cost, good adaptability and online production ability [5].

$\mathrm{Sn}-\mathrm{Pb}$ series solders, $\mathrm{Cd}-\mathrm{Zn}$ series solders, $\mathrm{Sn}$-Zn series solders, $\mathrm{Zn}$-Al series solders are the common solders of the copper aluminum brazing filler metals. $\mathrm{Pb}$ and $\mathrm{Cd}$ are toxic metal elements in $\mathrm{Sn}-\mathrm{Pb}$ series solders and Cd-Zn series solders. People contact with the lead-based substances for long time will lead central nervous system and reproductive system disorder, neurological and Physical develop slowly. Lead poisoning is great harm to their children's nerves system and physical development[6].solder which contain $\mathrm{Pb}, \mathrm{Cd}$ are used under limited; the corrosion resistance of zinc eutectic solder is poor, this kind of solder's research which using in copper and aluminum brazing of dissimilar materials is relatively less. Zinc-Al series solder which has good comprehensive properties are used widely and are studied more.

This paper mainly analyzes the addition of trace amounts of mixed rare earth element LaNd to have influence on the physical properties of Zn9.3 Al7Cu solder alloy to provide support for Zn9.3 Al7Cu solder's popularization and application.

\section{Experimental materials and methods}

Solder preparation. The raw materials for testing were the Zn grain, copper, aluminum whose purity are $99.95 \%$ and powder of LaNd. According to Table 1, Zn grain copper, aluminum and powder of 
LaNd are prepared.

Table.1 Series of examined ZnAlCuRE solder alloy

\begin{tabular}{lcccc}
\hline Number & 1 & 2 & 3 & 4 \\
\hline Rare earth content(wt.\%) & 0 & 0.1 & 0.3 & 0.5 \\
\hline Initial alloy & \multicolumn{4}{c}{ Zn-9.3Al-7Cu } \\
\hline
\end{tabular}

Zn grain, copper, aluminum and powder of La Nd were quantified on the electronic balance, and then melted them in the box-type resistance furnace with the heating temperature $1200^{\circ} \mathrm{C}$.In order to prevent oxidation of the solder alloy, $\mathrm{NaCl}: \mathrm{KCl}=1$ : 2 were covered the surface of the raw material as a protective agent during smelting process.

Density. The density of the solder alloys were measured with AR224CN electronic scales with density testerdifferential,First, measured mass $\mathrm{m}_{1}$ of the sample in the air,and then measured mass $\mathrm{m}_{2}$ in the water, according to Archimedes' principle:

$F=\rho_{1} \mathrm{~g} \mathrm{~V}=\left(\mathrm{m}_{1}-\mathrm{m}_{2}\right) \mathrm{g}$

And then derived the density formula:

$\rho=\rho_{1} \frac{\mathrm{m}_{1}}{\mathrm{~m}_{1}-\mathrm{m}_{2}}$

Where $\rho_{1}$ was density of water $\left(1 \mathrm{~g} / \mathrm{m}^{3}\right)$; $\mathrm{m}_{1}$ was solder mass in the air; $\mathrm{m}_{2}$ was solder; density in water, $\rho$ was density of solder.

Resistivity. The resistivity casted sample of the above solder alloys was shown in Figure 1 Length and diameter were measured by Vernier caliper and the resistance was measured by a precision ohmmeter. Then the resistivity $\mathrm{K}$ was calculated according to equation (3).

$$
k=R \times \frac{s}{l}
$$

Where k was resistivity $(\Omega . \mathrm{m})$, R was resistance $(\Omega)$, S was cross-sectional area $\left(\mathrm{m}^{2}\right)$, l was length (m).

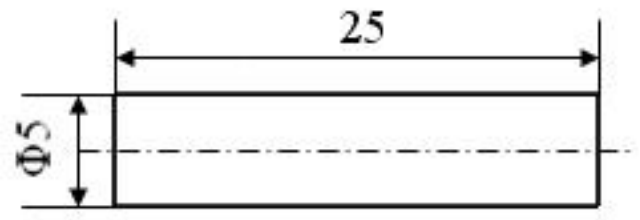

Fig. 1 the resistivity of solder sketch

\section{Results and discussions}

Effect of the content of RE on the density of Zn9.3Al7Cu solder alloy

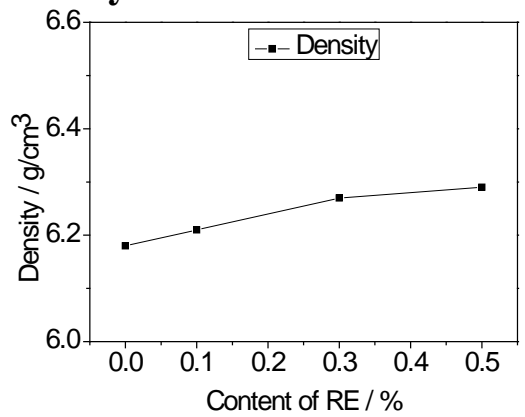

Fig.2 The density of Zn9.3Al7CuxLaNd solder alloy

Density is an important physical property of solder. Effect of the content of RE on the density of Zn9.3Al7Cu solder alloy was shown in Figure 2, it could be seen that solder density increased with the increasing of rare earth content increased but it was not obvious. When $\mathrm{RE}$ content is $0.5 \mathrm{wt} \%$, the $\mathrm{Zn} 9.3 \mathrm{Al7Cu} 0.5 \mathrm{RE}$ has the greatest density, is $6.29 \mathrm{~g} / \mathrm{cm} 3$ which is just $1.73 \%$ bigger than the matrix solder $\left(6.19 \mathrm{~g} / \mathrm{cm}^{3}\right)$. 
Figure 3 and figure 4 shows the XRD of Zn9.3Al7CuxRE solder alloys, show that, Zn9.3Al7Cu consists of the $(\mathrm{Zn})$ phase and $\varepsilon\left(\mathrm{CuZn}_{5}\right)$ phase, after the rare earth $\mathrm{LaNd}$ was added to $\mathrm{Zn} 9.3 \mathrm{Al} 7 \mathrm{Cu}$ solder alloy, no new phase was produced.it indicated that the main reason to the effect of RE on solder alloy density was not new phase producing.

The density of matrix solder alloy Zn9.3Zl7Cu is $6.19 \mathrm{~g} / \mathrm{cm}^{3}$, and the densities of La, Nd are $6.7 \mathrm{~g}$ $/ \mathrm{cm}^{3}$ and $7.0 \mathrm{~g} / \mathrm{cm}^{3}$ which are large than the density of matrix solder alloy, this may be the main reason that Zn9.3Al7CuxRE solder densities increased with the increasing of rare earth LaNd content increased. Because the addition of rare earth will cause the solder density increases, increased unit volume of solder alloy cost, and the RE are expensive, so rare earth should not be added too much. Preliminary research showed when RE content was $0.1 \mathrm{wt} \%$, the liquid-solid temperature range of Zn9.3Al7Cu0.1RE was the most narrow, is about $37^{\circ} \mathrm{C}$, that is $7{ }^{\circ} \mathrm{C}$ less than the matrix. This is Conducive to solder wetting on the base material, and taking into account the cost of solder, comprehensive studies have shown that: under the experimental conditions, the rare earth content of $0.1 \%$ is appropriate.
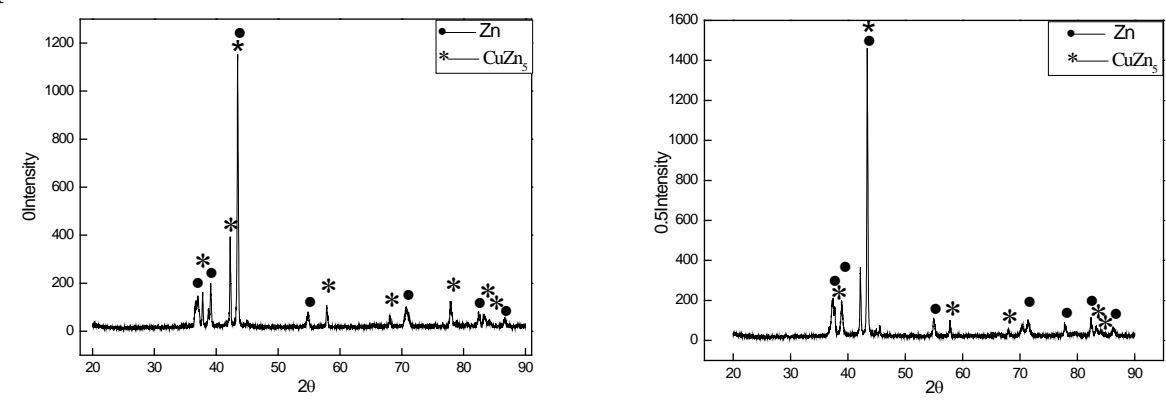

Fig.3 XRD of Zn9.3Al7Cu solder alloy Fig.4 XRD ofZn9.3Al7Cu0.5RE solder alloy

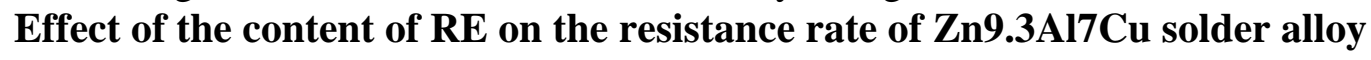

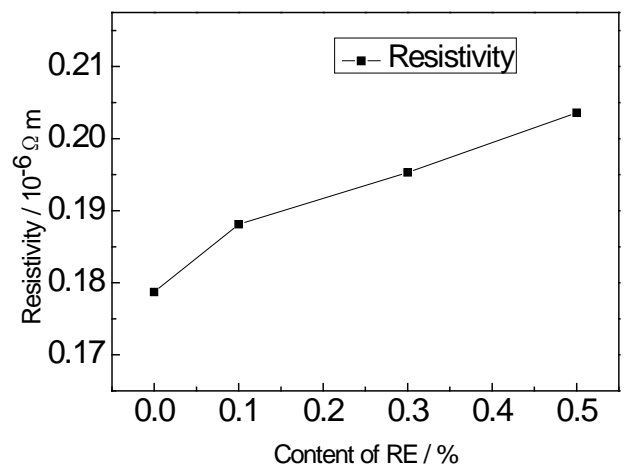

Fig.5 The resistance rate of Zn9.3Al7CuxLaNd solder alloy

Effect of the content of RE on the resistance rate of Zn9.3Al7Cu solder alloy was shown in Figure 5 , it could be seen that solder resistance rate increased with the increasing of rare earth content

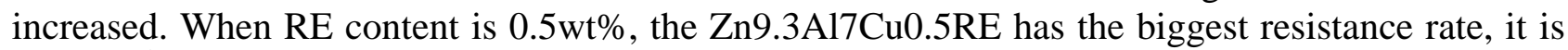
$0.2 \times 10^{-6} \Omega \mathrm{m}$ which is about $11 \%$ bigger than the matrix solder.

The resistance rate of solder alloy mainly is associated with the movement of free electrons, the adding of RE made the lattice distortion increase, increased the resistance of free electron motion which were in the solder alloy. So the resistance rate of solder alloy increased [7-9].

Figure 6(a) shows the SEM microstructure of Zn9.3Al7Cu solder alloy, it could be seen that the microstructure characteristic of $\mathrm{Zn} 9.3 \mathrm{Al} / \mathrm{Cu}$ alloy is large gray dendritic $\varepsilon\left(\mathrm{CuZn}_{5}\right)$ phase distributed on gray white matrix of $\eta(\mathrm{Zn}), \alpha(\mathrm{Al})$ phase was closed to $\varepsilon(\mathrm{CuZn} 5)$ phase, $\beta(\mathrm{ZnAl})$ phase was closed to $\alpha(\mathrm{Al})$ phase. Figure 6(b),(c),(d)show the SEM microstructure of Zn9.3Al7Cu solder alloy which contained rare earth, it could be seen that Large dendritic $\varepsilon\left(\mathrm{CuZn}_{5}\right)$ phase broke ,became smaller, and dispersed homogeneously, it also can say that the adding of RE LaNd refined alloy, increased grain boundaries, and made the resistance rate of $\mathrm{Zn9.3Al7Cu}$ solder alloy increase, at the same time the alloy lattice distortion increased, this increased the moving resistance of free electrons, and further made the resistance rate increase. This is because RE provided more nucleation particles for $\varepsilon$ 
$\left(\mathrm{CuZn} \mathrm{n}_{5}\right)$ phase, $\mathrm{RE}$ was the metamorphism in solder alloy to some extent, It is because of the role of $\mathrm{RE}$ had refined grains, resulted the resistance rate of Zn9.3Al7CuxRE solder alloy increasing.
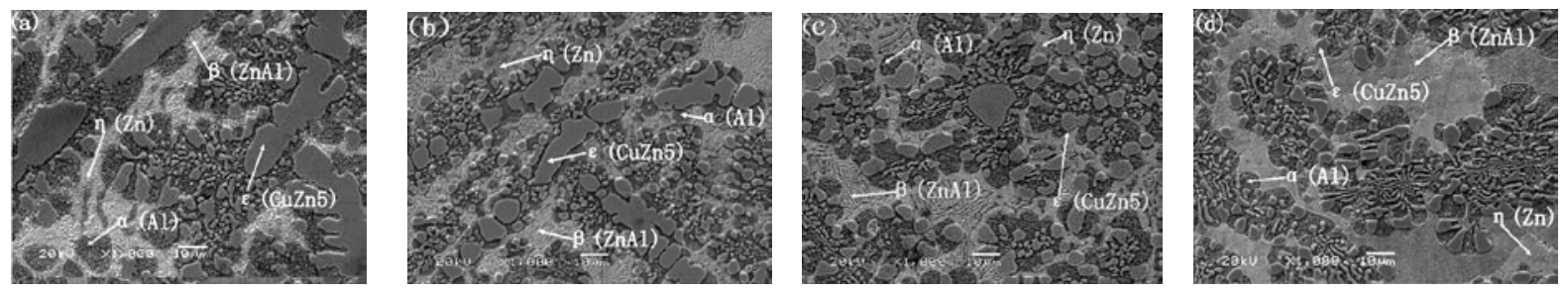

(a) Zn9.3Al7Cu

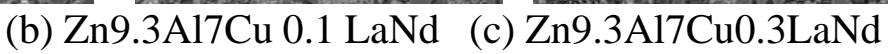

(d) Zn9.3Al7Cu0.5LaNd

Fig 6 Microstructure of Zn9.3Al7CuxLaNd solder alloy

It can be seen that the adding of $\mathrm{RE}$ to $\mathrm{Zn9.3Al7Cu}$ solder alloy, one can refine the grain, improve strength of solder alloy, on the other hand, it can raise the resistance rate of solder alloy, reduce conductivity of solder alloy, so rare earth content should not be added too much. On the scope of the study, $0.1 \%$ RE content is appropriate.

\section{Conclusions}

1.the density of solder alloys increases with the increasing of the content of rare earth LaNd, When $\mathrm{RE}$ content is $0.5 \mathrm{wt} \%$,the density is about $1.73 \%$ bigger than the matrix solder; because RE costs relatively high, so the content of RE is not too much.

2.the resistivity of solder alloys increases with the increasing of the content of rare earth LaNd, the resistivity reaches the greatest value When $\mathrm{RE} \mathrm{LaNd}$ content is $0.5 \mathrm{wt} \%$, he greatest value is $0.2 \times 10^{-6} \Omega \mathrm{m}$ which is about $11 \%$ bigger than the matrix solder, so the content of RE is not too much.

\section{References}

[1]lacaze J, Tierce S, Lafont M C, et al. Study of the microstructure resulting from brazed aluminium materials used in heat exchangers[J].Materials Science and Engineering A,2005,423:317-321.

[2]Mai T A, Spowage A C, Characterisation of dissimilar joints in laser weding of steel-kovar, copper -steel and copper-aluminium [J].Materials Science and Engineering A,2004,347(1-2):224-233.

[3]YANG Liu-bo,S UN De-ming,LIU Peng Li Jing. Research status of solder and weldability for $\mathrm{Cu} / \mathrm{Al}$ dissimilar materials [J] Welding Technology, 2011, 40(5):1-4.

[4]HUANG Bai yun.Status and developing strategy for China's nonferrous metal materials industry [J]. The Chinese Journal of Nonferrous Metals, 2004, 14Sl (5):122-127.

[5]LIU Huijie, SHEN Jun jun.Research for Cu/Al dissimilar Welding Welding Joining, 2009(3):1418.

[6] HUANG Xing WU Cheng ji.Effects of Pb on environmental pollution and human health [J]. Occupation health and occupational diseases, 1994, 9(2):116-119.

[7]Dusko Minic, Ales Kroupa, Dragana Zivkovi, Zivan Zivkovi, Manasijevi. Phase equilibria and thermo- dynamics of the Bi-Sb-Sn ternary system. Dragan [J].Journal of Alloys and Compounds, 2007(43- 8):150-157.

[8]Rasad R P. Surface Mount Technology Principle and Practice [M].New York: Van Nastrangeinheid, 1989:215-228.

[9]Suganuma Caki. Lead Free Soldering Technology [M].Beinjing Science Press. 2004:62-66. 